Araştırma Makalesi / Research Article
Geliş tarihi / Received: 01-01-2021
Kabul tarihi / Accepted: 05-05-2021

\title{
Mentha piperita'nın Çelikle Çoğaltılması Üzerine Farklı Ortam Hormon ve Hormon Dozlarının Etkisi
}

\section{Meryem YEŞIL ${ }^{1 *}$, Mehmet Muharrem ÖZCAN ${ }^{2}$}

ÖZET: Bu çalışma, Mentha piperita türüne ait çeliklerde, farklı köklendirme ortamları (perlit, torf, perlit-torf) ve naftalin asetik asit (NAA) ile indol-3-bütirik asit'in (IBA) 0, 1000, 2000, 3000, 4000 ppm dozlarının köklenmeye etkilerini saptamak amacıyla yapılmıştır. Sera ortamında gelişimini tamamlayan çeliklerde köklenme oranı (\%), kök sayısı (adet), en fazla kök uzunluğu ( $\mathrm{mm}$ ), sürgün sayısı (adet), sürgün uzunluğu (mm) ve yaprak sayısı (adet) incelenmiştir. Tüm deneme faktörleri, çeliklerde \%100 köklenme sağlamıştır. En fazla kök sayısı IBA hormonunun perlit ortamında 2000 ppm dozu ile ortaya çıkmış, en fazla kök uzunluğu NAA'in perlit ortamında gelişen çeliklerinde tespit edilmiştir. Sürgün sayısında ise IBA'nın torf ortamında $1000 \mathrm{ppm}$ dozu, sürgün uzunluğunda ve yaprak sayısında NAA'in torf ortamında 1000 ppm ile muameleye tabii tutulmuş çelikleri ön plana çıkmıştır. Mentha piperita bitkisinde kaliteli fide eldesi için torf köklendirme ortamı, NAA hormonu ve NAA'in 1000 ppm dozunun olumlu etkide bulunduğu saptanmıştır.

Anahtar Kelimeler: İndol-3-bütirik asit, köklendirme ortamı, Mentha piperita, naftalin asetik asit

\section{Effects of Plant Growth Regulators and Their Doses on Cutting Propagation of Mentha piperita at Different Rooting Media}

\begin{abstract}
This study was carried out to determine the effects of different naphthalene acetic acid (NAA) and indole-3-butyric acid (IBA) concentration [0, 1000, 2000, 3000, $4000 \mathrm{ppm}$ ] at different rooting media [perlite, peat, perlite-peat] on rooting in cuttings of the Mentha piperita species. Rooting rate (\%), root number, longest root length $(\mathrm{mm})$, shoot number, shoot length $(\mathrm{mm})$ and leaf number (number) were determinated on stem cuttings that completed their development in the greenhouse environment. Rooting was observed $100 \%$ in cuttings for all trial factors. The highest root number emerged with 2000 ppm dose of IBA hormone in perlite medium and the highest root length was detected in the cuttings of NAA growing in perlite environment. Applications of IBA $1000 \mathrm{ppm}$ dose in peat medium and NAA $1000 \mathrm{ppm}$ dose in peat medium stand out in terms of their effects on the number of shoots and shoot length, respectively. The highest number of leaves was determined at $1000 \mathrm{ppm}$ dose of NAA in peat medium. It was determined that peat rooting medium, NAA hormone, and its $1000 \mathrm{ppm}$ dose had a positive effect on obtaining quality seedlings in the Mentha piperita plant.
\end{abstract}

Keywords: Indole 3 butyric acid, Mentha piperita, naphthalene acetic acid, rooting media

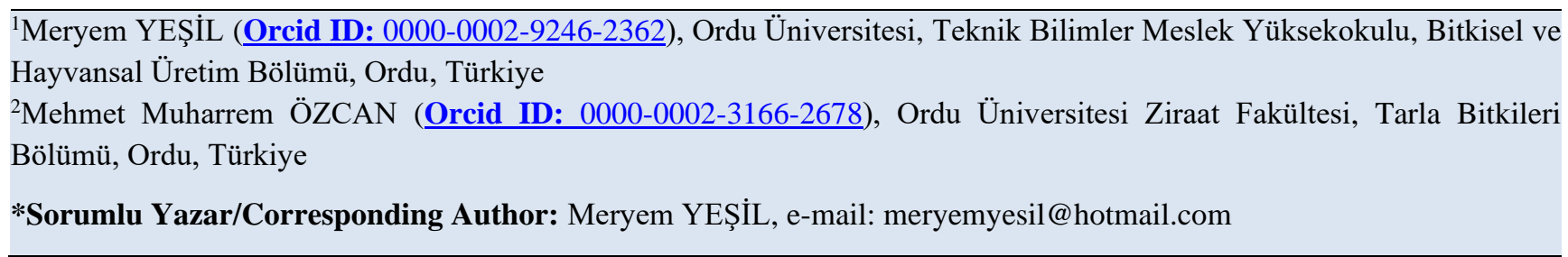




\section{GíRiș}

Peppermint olarak da bilinen Mentha piperita Lamiaceae familyasına ait olan endüstriyel olarak çeşitli kullanıma sahip dünyanın pek çok bölgesinde yetiştiriciliği yapılan çok yıllık tıbbi ve aromatik özellikteki bir bitkidir (Herro ve Jacob, 2010). Mentha piperita türüne ekonomik önem kazandıran unsur 30'dan fazla bileşen içeren uçucu yağıdır. Bu uçucu yağın en önemli bileşenleri mentol (\%33-60), menthon (\%15-32), isomenhton (\%2-8), 1,8-cineole (eucalyptol) (\%5-13), menthyl acetate (\%2-11), menthofuran (\%1-10) ve limonene (\%1-7)'dir (McKay ve Blumberg, 2006). Nane yağı ve bileşenleri ticari olarak gıda, ilaç ve kozmetik endüstrilerinin hammaddesidir. Mentol, macun, diş macunu, şekerleme, ağız spreyleri, analjezik merhemler, öksürük şurupları, parfümler, sakızlar, şekerlemeler ve tütün endüstrisinde hammadde olarak kullanılmaktadır. Tütün endüstrisi, ilaç ve şekerleme endüstrilerinin ardından toplam yağ tüketiminin yaklaşı \% 40 'ını oluşturmakta, taze veya kurutulmuş yapraklarından baharat olarak da faydalanılmaktadır (Singh ve ark., 2015).

Ekonomik önemi yüksek olan $M$. piperita türünde hem kromozom sayısının stabil olmamasından hem de mayotik eşleşmelerinin düzensiz ve karışık olmasından dolayı polen ve tohum sterilitesi oldukça yüksektir (Baydar, 2019). Tohum ile çoğaltılması zor olan tıbbi ve aromatik bitkilerde vejetatif olarak çoğaltma mümkün olmaktadır (Baydar, 2009). Bu sebeple $M$. piperita türünde de pratikte çelik ile çoğaltım yöntemi uygulanmaktadır. Bitkilerin vejetatif olarak çoğaltılmasında büyüme düzenleyicileri (oksin, sitokinin, etilen, absisik asit, giberellin) kök gelişimini ve köklenme oranını artırmak amacıyla kullanılmakta, indol asetik asit (IAA), indol bütirik asit (IBA), naftalin asetik asit (NAA), naftoksi asetik asit (NOAA), fenoksi asetik asit (FOAA), 2,4-D, fenil asetik asit (FAA), parakloro fenoksi asetik asit (4-CPA), 2,4,5-triklorofenoksi asetik asitde oksin türevleri olarak bilinmektedir (Kumlay ve Eryiğit, 2011). Ancak günümüzde en fazla kullanılan bitki büyüme düzenleyicisi düşük toksisite ve yüksek kök oluşturma kabiliyeti olan IBA (İndol-3 bütirik asit)'dır (Eriş, 2003).

Köklendirme ortamları ile ilgili yapılan çalışmalar hormon uygulamaları konusunda yapılan çalışmalar kadar yoğun olmamakla birlikte araştırıcılar ve çiftçiler tarafından en yaygın olarak kullanılan ortam perlittir. Yüksek su içeriğine sahip amorf volkanik bir cam olan perlit, mineral veya besin maddesi içermemekte toprağın yapısını değiştirmek için kullanılmaktadır. Torf ise ağırlığının 20 katı kadar su absorbe etmekte, 6-7 arası pH'ya sahip olmakta, \% 80 organik madde, $\% 1$ organik azot ve \% 46 organik karbon içermektedir (İzgi, 2020).

$\mathrm{Bu}$ çalışmada, farklı köklendirme ortamları, hormonlar ve hormon dozlarının Mentha piperita çeliklerinin köklenmesine etkisi araştırılmıştır.

\section{MATERYAL VE METOT}

Mentha piperita türü, Ordu Üniversitesi Ziraat Fakültesi Tibbi ve Aromatik Bitkiler Koleksiyon Bahçesinden temin edilmiş ve bitkinin $12 \mathrm{~cm}$ uzunluğundaki uç çelikleri kullanılmıştır. Köklendirme ortamı olarak perlit, torf ve perlit/torf karışımı (3 perlit / 1 torf) büyüme düzenleyici olarak IAA (İndol asetik asit) ve NAA (Naftalin asetik asit)'in 0 ppm, 1000 ppm, 2000 ppm, 3000 ppm, 4000 ppm dozlar1 kullanılmıştır. Deneme, 18 Mayıs 2018 tarihinde tesadüf parsellerinde faktöriyel düzenlemelere göre 3 tekrarlı, her tekrarda 4 çelik olacak şekilde IAA ve NAA hormon dozlarına 10 sn daldırılarak viollere dikilmiştir. Çeliklerin ihtiyacına göre gerekli sulama yapılmış ve gelişmelerini tamamlayan çelikler 26 Haziran 2018 tarihinde sökülerek akan su altında yıkanmış ve köklenme oranı (\%), kök sayısı (adet), en fazla kök uzunluğu ( $\mathrm{mm}$ ), sürgün sayısı (adet), sürgün uzunluğu (mm), yaprak sayısı (adet) belirlenmiştir. Araştırmadan elde edilen veriler SAS-JMP 10.0 paket programında tesadüf parsellerinde faktöriyel düzenlemelere göre analiz edilmiş ve çoklu karşılaştırma testlerinden LSD testi kullanılmıştır. 


\section{BULGULAR VE TARTIŞMA}

\section{Köklenme Oranı (\%)}

Denemeyi oluşturan tüm faktörlerde çeliklerin tamamında köklenme tespit edildiği için istatistik analize dahil edilmemiştir (Çizelge 1). Benzer şekilde Üre (2000) Origanum onites L. ve Origanum vulgare L'de, Kalyoncu ve ark. (2016) Salvia officinalis çeliklerinde farklı dozlarda IBA uygulamasında \%100 köklenme belirlemişlerdir. Kuris ve ark. (1980)'de M. piperita'da IBA ve IAA'in perlit-torf ortamında (1:1) köklenme oranına etkisini inceledikleri çalışmalarında her iki köklendirme hormonunun da \%100 köklenme sağladığını bildirmişlerdir. Yavaşi (2012)’nin de belirttiği üzere çeliklerin köklenmesine, bitkinin genetik yapısı ve yapısındaki hormonlar gibi bir takım iç faktörler ile gübreleme, sulama, çelik alma zamanı, yapraklanma ve büyüme gözü sayısı, köklendirme ortamı, ortam sıcaklı̆̆ı, ortam nemi ve köklendirme hormonları gibi tarımsal uygulamalar ile çevresel faktörlerin etki ettiği bilinmektedir.

Çizelge 1. Mentha piperita çeliklerinde köklenme oranı (\%)

\begin{tabular}{ccccccc}
\hline \multirow{2}{*}{ Hormon } & \multirow{2}{*}{ Ortam } & \multicolumn{5}{c}{ Doz (ppm) } \\
\cline { 3 - 7 } & Perlit & $\% 100$ & $\% 100$ & $\% 100$ & $\% 100$ & $\% 100$ \\
\multirow{2}{*}{ NAA } & Torf & $\% 100$ & $\% 100$ & $\% 100$ & $\% 100$ & $\% 100$ \\
& Perlit-Torf & $\% 100$ & $\% 100$ & $\% 100$ & $\% 100$ & $\% 100$ \\
\hline \multirow{2}{*}{ İBA } & Perlit & $\% 100$ & $\% 100$ & $\% 100$ & $\% 100$ & $\% 100$ \\
& Torf & $\% 100$ & $\% 100$ & $\% 100$ & $\% 100$ & $\% 100$ \\
& Perlit-Torf & $\% 100$ & $\% 100$ & $\% 100$ & $\% 100$ & $\% 100$ \\
\hline
\end{tabular}

Kök Sayısı (adet)

Kök sayısı bakımından IBA uygulanarak perlit ortamında gelişen çeliklerde 12.09 adet, NAA uygulanarak torf ortamında gelişen çeliklerde ise 9.56 adet kök sayısının ortaya çıktığı görülmektedir. Ancak bu fark istatistiksel olarak önemli ( $\mathrm{p} \leq 0.05$ ) olmamıştır (Çizelge 2). Kaçar ve ark. (2009) Salvia officinalis L. ve Salvia triloba L. türlerini 1000 ppm IBA ile muamele ederek \%100 torf, \%80 torf + $\% 20$ perlit ve $\% 80$ torf $+\% 20$ ponza taşı ortamlarını kullanarak köklenme durumunu incelemişler, $\% 100$ torf ortamı dışında kalan diğer ortamların kök gelişimi için uygun ortamlar olduğunu belirtmişlerdir. Ayrıca Arslan ve ark. (1994) Salvia officinalis'de, Çağıl ve ark. (2019) Berberis thunbergii'de, İzgi (2020), R. damascena Mill'da yapmış oldukları çalışmalarında en yüksek kök sayısını perlitte elde ettiklerini bildirmişlerdir. Kullanılan ortamların kök sayısına etkisini belirten başka araştırmalara da ulaş1lmış (Kalyoncu, 1996; Uysal ve ark., 2010; Eed ve Burgoyne, 2015) ancak bu çalışmada kök sayısı bakımından köklendirme ortamlarının önemli $(\mathrm{p} \leq 0.05)$ olmadığı belirlenmiştir.

Hormon doz ortalamaları incelendiğinde de IBA'nın 2000 ppm dozunda 13.67 adet, hormon uygulanmayan kontrol bitkilerinde ise 9.69 adet kök sayısı tespit edilmiş ancak istatistiksel fark ortaya çıkmamıştır. Ancak her iki hormonun genel doz ortalamaları arasındaki fark önemli ( $\mathrm{p} \leq 0.05)$ olmuş en fazla kök sayısı 3000 ppm doz uygulanmış çeliklerde (12.36 adet) en az kök sayısı ise kontrol çeliklerinde (9.69 adet) tespit edilmiştir. Konu hakkında çalışma yapan Atıcı (2000) Rosmarinus officinalis çeliklerinde NAA'in 50,100, 150, 200 ppm dozlarının, Pulatkan ve ark. (2018)'de Berberis thunbergii'de IAA, IBA ve NAA'in farklı dozlarının köklenme üzerine etkisini incelemiş ve hormon uygulamasının kontrol bitkilerine göre kök sayısını artırdığını bildirmişlerdir. Ayanoğlu ve ark. (1999)'da IBA konsantrasyonlarındaki artışın çeliklerde kök sayısını teşvik ettiğini tespit etmişler, Şekeroğlu ve ark. (2001)'de Thymbra spicata L. türünde IBA uygulamasının kök sayısını olumlu yönde etkilediğini vurgulamışlardır. Ayrıca Üre (2000), Ilgın ve Bulat (2001), Özcan ve ark. (2013), Sağlam ve ark. (2014), Kalyoncu ve ark. (2016), Sarı ve Kaçar (2019)'da benzer sonuçlara ulaşmıştır. 
Ortam x hormon x doz için tanıtıcı istatistik değerleri Çizelge 2'de sunulmuş, üçlü interaksiyonun istatistiksel olarak önemli $(\mathrm{p} \leq 0.05)$ olduğu belirlenmiştir. Her iki hormon ve ortamlar incelendiğinde en fazla kök sayılarının 2000 ppm İBA dozunun perlit ortamında (16.72 adet), 4000 ppm IBA dozunun torf ortamında (15.80 adet) ve 1000 ppm NAA dozunun perlit ortamında (14.40 adet) uygulanması ile ortaya çıktığı görülmektedir. Çalışma sonuçlarını destekler şekilde Sağlam ve ark. (2014) Salvia fruticosa Mill.'de, Kalyoncu ve ark. (2016)'da adaçayı'nda IBA dozlarının bitki köklenmesine etkisini araştırdıkları çalışmalarında hormon uygulamasının bitkide köklenmeyi artırdığını belirtmişlerdir.

Çizelge 2. Mentha piperita çeliklerinde kök sayısı için tanıtıcı istatistik değerleri (adet)

\begin{tabular}{|c|c|c|c|c|c|c|c|}
\hline \multirow[b]{2}{*}{ Hormon } & \multirow[b]{2}{*}{ Ortam } & \multicolumn{5}{|c|}{ Doz (ppm) } & \multirow{2}{*}{$\begin{array}{c}\text { NAA } x \\
\text { Ortam } \\
\text { Ortalama }\end{array}$} \\
\hline & & 0 & 1000 & 2000 & 3000 & 4000 & \\
\hline \multirow{3}{*}{ NAA } & Perlit & $11.07^{\mathrm{e}^{-1}}$ & $14.40^{\mathrm{abc}}$ & $8.90^{\mathrm{ijk}}$ & $11.80^{\mathrm{chh}}$ & $10.50^{\mathrm{f}-\mathrm{j}}$ & 11.33 \\
\hline & Torf & $6.72^{\mathrm{k}}$ & $7.80^{\mathrm{jk}}$ & $11.90^{\mathrm{ch}}$ & $10.10^{\mathrm{g}-\mathrm{j}}$ & $11.30^{\mathrm{d}-1}$ & 9.56 \\
\hline & $\begin{array}{c}\text { Perlit- } \\
\text { Torf }\end{array}$ & $11.30^{\mathrm{d}-1}$ & $10.10^{g-j}$ & $11.10^{\mathrm{e}-1}$ & $14.10^{\mathrm{a}-\mathrm{d}}$ & $12.30^{\mathrm{c}-\mathrm{g}}$ & 11.78 \\
\hline $\begin{array}{l}\text { NAA Doz } \\
\text { Ortalama }\end{array}$ & & 9.69 & 10.77 & 10.63 & 12.00 & 11.37 & $\begin{array}{r}\text { İBA Ortam } \\
\text { Ortalama } \\
\end{array}$ \\
\hline \multirow{3}{*}{ İBA } & Perlit & $11.07^{\mathrm{e}-1}$ & $10.78^{\mathrm{f}-1}$ & $16.72^{\mathrm{a}}$ & $12.77^{\mathrm{c}-\mathrm{g}}$ & $9.10^{\mathrm{h}-\mathrm{k}}$ & 12.09 \\
\hline & Torf & $6.72^{\mathrm{k}}$ & $11.00^{\mathrm{e}-1}$ & $11.20^{\mathrm{e}-1}$ & $13.80^{\mathrm{b}-\mathrm{e}}$ & $15.80^{\mathrm{ab}}$ & 11.70 \\
\hline & $\begin{array}{c}\text { Perlit- } \\
\text { Torf }\end{array}$ & $11.30^{\mathrm{d}-1}$ & $10.60^{f-j}$ & $13.10^{b-f}$ & $11.60^{c-1}$ & $12.10^{\mathrm{c}-\mathrm{g}}$ & 11.74 \\
\hline $\begin{array}{l}\text { İBA Doz } \\
\text { Ortalama }\end{array}$ & & 9.69 & 10.79 & 13.67 & 12.72 & 12.33 & \\
\hline $\begin{array}{c}\text { Doz } \\
\text { Ortalama }\end{array}$ & & $9.69^{c}$ & $10.78^{\mathrm{bc}}$ & $12.15^{\mathrm{ab}}$ & $12.36^{\mathrm{a}}$ & $11.85^{\mathrm{ab}}$ & \\
\hline
\end{tabular}

Ortak harfi olmayan ortalamalar arasındaki fark istatistiksel olarak önemlidir $(\mathrm{p} \leq 0.05)$

\section{En Fazla Kök Uzunluğu (mm)}

Çizelge 3 yetiştirme ortamları bakımından incelendiğinde en fazla kök uzunluğunun NAA'in perlit (192.80 mm) ortamında uygulanması sonucunda en az kök uzunluğunun ise IBA ile muamele edilmiş çeliklerin torf ortamında $(134.99 \mathrm{~mm})$ gelişmesi ile ortaya çıktığ görülmektedir. Bu fark istatistiki olarak $\mathrm{p} \leq 0.05$ seviyesinde önemli $(\mathrm{p} \leq 0.05)$ olmuştur. Çalışma ile uyumlu olarak bazı araştırıcılarda en uzun kök değerlerini perlit ortamında gelişim gösteren bitkilerde tespit etmişlerdir (Arslan ve ark. 1994; Kelen ve Demirtaş, 2001; İzgi, 2020). Perlit ortamında en fazla kök uzunluğunun belirlenmesi bu ortamın drenajının ve kök havalandırmasının iyi olması, suyu ve bitki besin maddelerini köklerin yararlanabileceği formda tutmasından kaynaklanmış olabilir (Yavaşi, 2012).

Her iki hormonun doz ortalamaları incelendiğinde NAA' in 3000 ppm dozu $188.87 \mathrm{~mm}$, IBA'nın 2000 ppm dozu $144.73 \mathrm{~mm}$ ile en kısa kök uzunluklarını ortaya çıkarmasına rağmen aradaki matematiksel fark en fazla kök uzunluğu üzerinde istatistiksel olarak önemli $(\mathrm{p} \leq 0.05)$ etkide bulunmamıştır. Genel doz ortalamasında da benzer durum ortaya çıkmıştır $(p \leq 0.05)$. Bu sonuç hormon dozlarının en fazla kök uzunluğunu istatistiki olarak etkilediğini belirten araştırıcıların bulgularıyla uyumlu olmamış (Chauhan ve ark. 1992; Ayanoğlu ve ark., 1999; Kalyoncu ve ark., 2009; Kara ve ark., 2011; Kalyoncu ve ark. 2016; Pulatkan ve ark. 2018) ancak kök uzunluğunun IBA dozlarından etkilenmediğini belirten Althaus ve ark. (2005)'in bulgusu ile uyumlu olmuştur.

Ortam x hormon x doz interaksiyonu incelendiğinde perlit ortamında $206.68 \mathrm{~mm}$, torf ortamında $145.83 \mathrm{~mm}$, perlit-torf ortamında $170.70 \mathrm{~mm}$ şeklinde ortaya çıkan kontrol çeliklerine ait en fazla kök uzunluğunun uygulanan muamelelerden istatistiksel olarak etkilenmediği görülmektedir. 
Çizelge 3. Mentha piperita çeliklerinde en fazla kök uzunluğu için tanıtıcı istatistik değerleri (mm)

\begin{tabular}{|c|c|c|c|c|c|c|c|}
\hline \multirow[b]{2}{*}{ Hormon } & \multirow[b]{2}{*}{ Ortam } & \multicolumn{5}{|c|}{ Doz (ppm) } & \multirow{2}{*}{$\begin{array}{c}\text { NAA } x \\
\text { Ortam } \\
\text { Ortalama }\end{array}$} \\
\hline & & $\mathbf{0}$ & 1000 & 2000 & 3000 & 4000 & \\
\hline \multirow{3}{*}{ NAA } & Perlit & 206.68 & 173.00 & 196.90 & 192.90 & 194.50 & $192.80^{\mathrm{a}}$ \\
\hline & Torf & 145.83 & 177.90 & 167.30 & 188.80 & 173.30 & $170.63^{\mathrm{b}}$ \\
\hline & $\begin{array}{c}\text { Perlit- } \\
\text { Torf }\end{array}$ & 170.70 & 195.80 & 168.70 & 184.90 & 186.20 & $181.26^{\mathrm{ab}}$ \\
\hline $\begin{array}{l}\text { NAA Doz } \\
\text { Ortalama }\end{array}$ & & 174.40 & 182.23 & 177.63 & 188.87 & 184.67 & $\begin{array}{c}\text { İBA x } \\
\text { Ortam } \\
\text { Ortalama }\end{array}$ \\
\hline \multirow{3}{*}{ İBA } & Perlit & 206,68 & 183.60 & 148.98 & 186.97 & 192.53 & $183.75^{\mathrm{ab}}$ \\
\hline & Torf & 145.83 & 138.40 & 129.20 & 133.00 & 128.50 & $134.99^{\mathrm{d}}$ \\
\hline & $\begin{array}{c}\text { Perlit- } \\
\text { Torf }\end{array}$ & 170.70 & 144.10 & 156.00 & 153.00 & 158.70 & $156.50^{c}$ \\
\hline $\begin{array}{l}\text { İBA Doz } \\
\text { Ortalama }\end{array}$ & & 174.40 & 155.37 & 144.73 & 157.66 & 159.91 & \\
\hline $\begin{array}{c}\text { Doz } \\
\text { Ortalama }\end{array}$ & & 174.40 & 168.80 & 161.18 & 173.27 & 172.29 & \\
\hline
\end{tabular}

Ortak harfi olmayan ortalamalar arasındaki fark istatistiksel olarak önemlidir $(\mathrm{p} \leq 0.05)$

\section{Sürgün Sayısı (adet)}

Çizelge 4'de köklendirme ortamlarının sürgün sayıları üzerine etkisi incelenecek olursa en fazla sürgün sayılarının IBA hormonu ile muamele edilmiş çeliklerin perlit-torf ortamında (10.94 adet) ve torf ortamında (10.17 adet) geliştirilmesi ile ortaya çıktığı görülmektedir. En az sürgün sayıları ise istatistiksel olarak aynı grupta yer almış ve yine IBA hormonunun perlit ortamında (6.15 adet), NAA hormonunun perlit (6.34 adet) ve torf ortamlarında ( 6.17 adet) uygulanması ile ortaya çıkmış bu durum istatistiki olarak önemli $(\mathrm{p} \leq 0.05)$ olmuştur. Benzer şekilde Çağıl ve ark. (2019), farklı ortamların Berberis thunbergii' de köklenme üzerine etkisini inceledikleri çalışmalarında sürgün sayısı bakımından köklendirme ortamları arasında fark olduğunu belirtmiş en fazla sürgün sayısının pomza'da elde edildiğini ikinci sırada ise torf ve vermikülit ortamlarının yer aldığını bildirmiştir.

Çizelge 4. Mentha piperita çeliklerinde sürgün sayısı için tanıtıcı istatistik değerleri (adet)

\begin{tabular}{|c|c|c|c|c|c|c|c|}
\hline \multirow{2}{*}{ Hormon } & \multirow{2}{*}{ Ortam } & \multicolumn{5}{|c|}{ Doz (ppm) } & \multirow{2}{*}{$\begin{array}{c}\text { NAA x } \\
\text { Ortam } \\
\text { Ortalama }\end{array}$} \\
\hline & & $\mathbf{0}$ & 1000 & 2000 & 3000 & 4000 & \\
\hline \multirow{3}{*}{ NAA } & Perlit & $6.93^{\text {fgh }}$ & $5.90^{\mathrm{gh}}$ & $6.00^{\mathrm{gh}}$ & $7.00^{\mathrm{fg}}$ & $5.90^{\mathrm{gh}}$ & $6.34^{\mathrm{d}}$ \\
\hline & Torf & $6.97^{\mathrm{fgh}}$ & $5.30^{\mathrm{h}}$ & $7.10^{\mathrm{fg}}$ & $5.50^{\mathrm{gh}}$ & $6.00^{\mathrm{gh}}$ & $6.17^{\mathrm{d}}$ \\
\hline & $\begin{array}{c}\text { Perlit- } \\
\text { Torf }\end{array}$ & $10.80^{\mathrm{abc}}$ & $9.80^{\mathrm{bcd}}$ & $9.70 b^{\mathrm{bcd}}$ & $8.90^{\mathrm{de}}$ & $7.70^{\mathrm{ef}}$ & $9.38^{c}$ \\
\hline $\begin{array}{l}\text { NAA Doz } \\
\text { Ortalama }\end{array}$ & & $8.23^{\mathrm{bc}}$ & $7.00^{\mathrm{de}}$ & $7.60^{\mathrm{cd}}$ & $7.13^{\mathrm{de}}$ & $6.53^{\mathrm{e}}$ & $\begin{array}{c}\text { İBA x } \\
\text { Ortam } \\
\text { Ortalama }\end{array}$ \\
\hline \multirow{3}{*}{ İBA } & Perlit & $6.93^{\mathrm{fgh}}$ & $5.78^{\mathrm{gh}}$ & $5.42^{\mathrm{gh}}$ & $6.45^{\mathrm{fgh}}$ & $6.15^{\text {fgh }}$ & $6.15^{\mathrm{d}}$ \\
\hline & Torf & $6.97^{\mathrm{fgh}}$ & $11.90^{\mathrm{a}}$ & $11.30^{\mathrm{ab}}$ & $9.60^{\mathrm{cd}}$ & $11.10^{\mathrm{abc}}$ & $10.17^{\mathrm{b}}$ \\
\hline & $\begin{array}{c}\text { Perlit- } \\
\text { Torf }\end{array}$ & $10.80^{\mathrm{abc}}$ & $10.60^{\mathrm{abc}}$ & $11.70^{\mathrm{a}}$ & $11.90^{\mathrm{a}}$ & $9.70^{\mathrm{bcd}}$ & $10.94^{\mathrm{a}}$ \\
\hline $\begin{array}{l}\text { İBA Doz } \\
\text { Ortalama }\end{array}$ & & $8.23^{\mathrm{bc}}$ & $9.43^{\mathrm{a}}$ & $9.47^{\mathrm{a}}$ & $9.32^{\mathrm{a}}$ & $8.98^{\mathrm{ab}}$ & \\
\hline $\begin{array}{c}\text { Doz } \\
\text { Ortalama } \\
\end{array}$ & & 8.23 & 8.22 & 8.54 & 8.23 & 7.76 & \\
\hline
\end{tabular}

Ortak harfi olmayan ortalamalar arasındaki fark istatistiksel olarak önemlidir $(\mathrm{p} \leq 0.05)$

NAA ve IBA hormon dozlarının da sürgün sayısını istatistiki olarak $(\mathrm{p} \leq 0.05)$ etkilediği görülmektedir. Çizelge 4 incelendiğinde kontrol bitkilerinde elde edilen sürgün sayısına (8.23 adet) göre 
IBA'nın 1000 ppm (9.43 adet), 2000 ppm (9.47 adet) ve 3000 ppm (9.32 adet) dozlarının sürgün sayısını artırdığı tespit edilmiş istatistiksel olarak bu dozlar aynı grupta yer almışlardır. Hormon uygulaması yapılmamış kontrol çeliklerinde (8.23 adet) elde edilen sürgün sayısına göre NAA hormonunun 1000 ppm (7.00 adet), 2000 ppm (7.60 adet), 3000 ppm (7.13 adet) ve 4000 ppm (6.53 adet) dozlarında sürgün sayısı azalmıştır. Ancak her iki hormonun genel doz ortalamaları incelendiğinde istatistiksel fark tespit edilmemiştir.

Çizelge 4'de yer alan ortam $\mathrm{x}$ hormon $\mathrm{x}$ doz üçlü interaksiyonunun istatistiki olarak $\mathrm{p} \leq 0.05$ seviyesinde önemli olduğu tespit edilmiştir. IBA hormonunun 1000 ppm (11.90 adet), 2000 ppm (11.30 adet), 4000 ppm (11.10 adet) dozlarının torf ortamında gelişen çeliklere uygulanması sonucunda kontrol bitkilerine göre daha fazla sürgün sayısı meydana getirdiği görülmektedir.

\section{Sürgün Uzunluğu (mm)}

Çizelge 5 incelendiğinde ortam ve hormon uygulamalarında sürgün uzunluğu için hem NAA'de (36.75 mm) hem de IBA'da $(28.72 \mathrm{~mm})$ torf yetiştirme ortamı birinci ve ikinci sırayı almış ve bu durum istatistiksel olarak önemli ( $\mathrm{p} \leq 0.05$ ) olmuştur. Kanimarani (2013)'de, Myrtus communes ve Berberis thunbergii türlerinin köklenmesine farklı köklendirme ortamlarının etkisini araştırmış ve Letonya kompostunun önemli derecede sürgün uzunluğunu artırdığını belirtmiştir. Çağıl ve ark. (2019) ise Berberis thunbergii' de en yüksek sürgün uzunluğunu pomza, vermikülit ve perlit ortamlarında tespit etmiştir.

Hormon dozlarının da sürgün uzunluğuna önemli $(\mathrm{p} \leq 0.05)$ etkide bulunduğu tespit edilmiş en fazla sürgün uzunlukları NAA'in 1000 ppm (26.06 mm), 2000 ppm (26.20 mm) ve 4000 ppm (25.68 mm) dozlarında ortaya çıkmıştır. IBA hormonun ise 1000 ppm $(19.33 \mathrm{~mm})$ ve 2000 ppm (18.60 mm) dozları sürgün uzunluğunu olumsuz yönde etkilemiş ve kontrol çeliklerinden $(22.67 \mathrm{~mm})$ daha az sürgün uzunluğu meydana getirmiştir.

Çizelge 5. Mentha piperita çeliklerinde sürgün uzunluğu için tanıtıcı istatistik değerleri (mm)

\begin{tabular}{|c|c|c|c|c|c|c|c|}
\hline \multirow[b]{2}{*}{ Hormon } & \multirow[b]{2}{*}{ Ortam } & \multicolumn{5}{|c|}{ Doz (ppm) } & \multirow{2}{*}{$\begin{array}{c}\text { NAA } x \\
\text { Ortam } \\
\text { Ortalama }\end{array}$} \\
\hline & & 0 & 1000 & 2000 & 3000 & 4000 & \\
\hline \multirow[t]{3}{*}{ NAA } & Perlit & $18.27^{\mathrm{h}-\mathrm{k}}$ & $15.34^{1-1}$ & $16.84^{\mathrm{h}-1}$ & $15.25^{1-1}$ & $20.47^{\mathrm{e}-\mathrm{h}}$ & $17.23^{\mathrm{d}}$ \\
\hline & Torf & $32.76^{c}$ & $41.75^{\mathrm{a}}$ & $38.60^{\mathrm{ab}}$ & $34.78^{b c}$ & $35.84^{\mathrm{bc}}$ & $36.75^{\mathrm{a}}$ \\
\hline & $\begin{array}{c}\text { Perlit- } \\
\text { Torf }\end{array}$ & $16.99^{\mathrm{h}-1}$ & $21.10^{\mathrm{e}-\mathrm{h}}$ & $23.16^{\mathrm{d}-\mathrm{g}}$ & $16.66^{\mathrm{h}-1}$ & $20.73^{\mathrm{e}-\mathrm{h}}$ & $19.73^{c}$ \\
\hline $\begin{array}{l}\text { NAA Doz } \\
\text { Ortalama }\end{array}$ & & $22.67^{b}$ & $26.06^{\mathrm{a}}$ & $26.20^{\mathrm{a}}$ & $22.23^{b}$ & $25.68^{\mathrm{a}}$ & $\begin{array}{c}\text { IBA x } \\
\text { Ortam } \\
\text { Ortalama }\end{array}$ \\
\hline \multirow{3}{*}{ İBA } & Perlit & $18.27^{\mathrm{h}-\mathrm{k}}$ & $13.89^{\mathrm{kl}}$ & $12.56^{1}$ & $14.55^{\mathrm{jkl}}$ & $13.57^{\mathrm{kl}}$ & $14.57^{\mathrm{e}}$ \\
\hline & Torf & $32.76^{c}$ & $24.61^{\mathrm{de}}$ & $24.14^{\mathrm{def}}$ & $34.21^{\mathrm{bc}}$ & $27.87^{\mathrm{d}}$ & $28.72^{\mathrm{b}}$ \\
\hline & $\begin{array}{c}\text { Perlit- } \\
\text { Torf }\end{array}$ & $16.99^{\mathrm{h}-\mathrm{l}}$ & $19.50^{\mathrm{f}-1}$ & $19.11^{g-j}$ & $19.19^{\mathrm{g}-\mathrm{j}}$ & $18.94^{g-j}$ & $18.74^{\mathrm{cd}}$ \\
\hline $\begin{array}{l}\text { İBA Doz } \\
\text { Ortalama }\end{array}$ & & $22.67^{b}$ & $19.33^{\mathrm{c}}$ & $18.60^{\mathrm{c}}$ & $22.65^{\mathrm{b}}$ & $20.13^{\mathrm{bc}}$ & \\
\hline $\begin{array}{c}\text { Doz } \\
\text { Ortalama }\end{array}$ & & 22.67 & 22.70 & 22.40 & 22.44 & 22.91 & \\
\hline
\end{tabular}

Ortak harfi olmayan ortalamalar arasındaki fark istatistiksel olarak önemlidir $(\mathrm{p} \leq 0.05)$

Ortam $\mathrm{x}$ hormon $\mathrm{x}$ doz verileri incelendiğinde $\mathrm{p} \leq 0.05$ seviyesinde istatistiksel fark olduğu görülmüş matematiksel olarak da en fazla sürgün uzunlukları NAA'in torf ortamında 1000 ppm (41.75 $\mathrm{mm})$ ve 2000 ppm (38.60 mm) olarak uygulanmasıyla ortaya çıkmıştır. 


\section{Yaprak Sayısı (adet)}

Fidelerdeki yaprak sayısı bakımından Çizelge 6 incelendiğinde, ortamlar arasındaki farkın istatistiki bakımdan önemli $(\mathrm{p} \leq 0.05)$ olduğu görülmektedir. En fazla yaprak sayısı 7.32 adet ile NAA uygulanmış çeliklerin torf ortamında gelişmesi sonucu ortaya çıkmış, ikinci sırayı ise IBA'nın yine torf ortamında uygulanmasıyla elde edilen çeliklerdeki yaprak sayıları (6.54 adet) almıştır. Diğer köklendirme ortamlarında ortaya çıkan yaprak sayıları ise istatistiksel bakımdan aynı grupta bulunmaktadır. Bu sonuç farklı köklendirme ortamlarının yaprak sayısı üzerine etkisini araştıran Kanimarani (2013) ve Çağıl ve ark. (2019)'un bulgularıyla uyumlu olmuştur.

NAA'in 1000 ppm dozunda ortaya ç1kan 6.40 adet yaprak sayıs1, 4000 ppm IBA uygulamas1 sonucunda 5.60 adet olarak belirlenmiş ve bu fark istatistiksel olarak önemli $(\mathrm{p} \leq 0.05)$ olmuştur. $\mathrm{Bu}$ bulgu Bhat ve ark. (2008)'in, Lavandula officinalis bitkisine uyguladıkları NAA ve IBA köklendirme hormonlarının 1000, 2000, 3000 ppm dozlarında en yüksek yaprak sayısını elde ettiklerini bildirdikleri çalışma ile kısmen uyumlu olmuştur. Bunun sebebi olarak çalışmalarda farklı cinslerin kullanılması olduğu düşünülmektedir.

Yaprak sayısı üzerinde ortam $\mathrm{x}$ hormon $\mathrm{x}$ dozun etkisi istatistiksel olarak önemli $(\mathrm{p} \leq 0.05)$ olmuş, en fazla yaprak sayısı NAA'in 1000 ppm uygulanmış çeliklerinin torf ortamında gelişmesiyle (8.28 adet), en az yaprak sayısı ise 4000 ppm IBA uygulanmış çeliklerin perlit ortamında geliştirilmesiyle (4.64 adet) elde edilmiştir.

Çizelge 6. Mentha piperita çeliklerinde yaprak sayısı için tanıtıcı istatistik değerleri (adet)

\begin{tabular}{|c|c|c|c|c|c|c|c|}
\hline \multirow[t]{2}{*}{ Hormon } & \multirow[t]{2}{*}{ Ortam } & \multicolumn{5}{|c|}{ Doz (ppm) } & \multirow{2}{*}{$\begin{array}{c}\text { NAA x } \\
\text { Ortam } \\
\text { Ortalama }\end{array}$} \\
\hline & & 0 & 1000 & 2000 & 3000 & 4000 & \\
\hline \multirow{3}{*}{ NAA } & Perlit & $5.86^{\mathrm{d}-\mathrm{h}}$ & $5.23^{\mathrm{g}-\mathrm{k}}$ & $5.27^{\mathrm{f}-\mathrm{k}}$ & $5.08^{\mathrm{ijk}}$ & $5.41^{e-j}$ & $5.37^{\mathrm{c}}$ \\
\hline & Torf & $6.87^{\mathrm{bc}}$ & $8.28^{\mathrm{a}}$ & $7.12^{\mathrm{b}}$ & $7.02^{\mathrm{b}}$ & $7.31^{\mathrm{b}}$ & $7.32^{\mathrm{a}}$ \\
\hline & $\begin{array}{l}\text { Perlit- } \\
\text { Torf }\end{array}$ & $5.44^{e-j}$ & $5.70^{\mathrm{d}-1}$ & $5.19^{\mathrm{g}-\mathrm{k}}$ & $5.17^{\mathrm{h}-\mathrm{k}}$ & $5.88^{\mathrm{d}-\mathrm{g}}$ & $5.47^{\mathrm{c}}$ \\
\hline NAA Doz & & $6.06^{\mathrm{abc}}$ & $6.40^{\mathrm{a}}$ & $5.86^{\mathrm{bcd}}$ & $5.76^{\mathrm{cd}}$ & $6.20^{\mathrm{ab}}$ & İBA x \\
\hline Ortalama & & & & & & & $\begin{array}{c}\text { Ortam } \\
\text { Ortalama }\end{array}$ \\
\hline \multirow{3}{*}{ İBA } & Perlit & $5.86^{\mathrm{d}-\mathrm{h}}$ & $5.51^{\mathrm{d}-\mathrm{j}}$ & $5.98^{\mathrm{de}}$ & $5.00^{\mathrm{jk}}$ & $4.64^{\mathrm{k}}$ & $5.40^{\mathrm{c}}$ \\
\hline & Torf & $6.87^{b c}$ & $6.19^{\mathrm{cd}}$ & $5.73^{\mathrm{d}-1}$ & $7.12^{\mathrm{b}}$ & $6.80^{\mathrm{bc}}$ & $6.54^{\mathrm{b}}$ \\
\hline & $\begin{array}{l}\text { Perlit- } \\
\text { Torf }\end{array}$ & $5.44^{e-j}$ & $5.58^{\mathrm{d}-\mathrm{j}}$ & $5.96^{\mathrm{def}}$ & $5.56^{\mathrm{d}-\mathrm{j}}$ & $5.36^{\mathrm{e}-\mathrm{j}}$ & $5.58^{\mathrm{c}}$ \\
\hline $\begin{array}{l}\text { İBA Doz } \\
\text { Ortalama }\end{array}$ & & $6.06^{\mathrm{abc}}$ & $5.76^{\mathrm{cd}}$ & $5.89^{\mathrm{bcd}}$ & $5.89^{\mathrm{bcd}}$ & $5.60^{\mathrm{d}}$ & \\
\hline $\begin{array}{c}\text { Doz } \\
\text { Ortalama }\end{array}$ & & 6.06 & 6.08 & 5.88 & 5.83 & 5.90 & \\
\hline
\end{tabular}

Ortak harfi olmayan ortalamalar arasındaki fark istatistiksel olarak önemlidir $(\mathrm{p} \leq 0.05)$

\section{SONUÇ}

Mentha piperita türünün çeliklerinde farklı köklendirme ortamlarının ve NAA ile IBA hormonlarına ait dozların köklenmeye etkilerini belirlemek için yapılan bu çalışmada çeliklerde \%100 köklenme tespit edilmiştir. Ancak kök sayısı, en fazla kök uzunluğu, sürgün sayısı, sürgün uzunluğu ve yaprak sayısı deneme faktörlerinden farklı şekilde etkilenmiştir. En yüksek değerler kök sayısında IBA x perlit x 2000 ppm dozunda, en fazla kök uzunluğu NAA x perlit ortamında, sürgün sayısı IBA x torf x 1000 ppm uygulamasında, sürgün uzunluğu ve yaprak sayısı ise NAA x torf x 1000 ppm dozunda 
ortaya çıkmıştır. Araştırmanın sonuçlarına göre Mentha piperita bitkisinin köklenmesi üzerine torf köklendirme ortamının ve NAA'in 1000 ppm dozunun olumlu etkide bulunduğu saptanmıştır.

\section{Çıkar Çatışması}

Makale yazarları aralarında herhangi bir çıkar çatışması olmadığını beyan ederler.

\section{Yazar Katkısı}

Yazarlar makaleye eşit oranda katkı sağlamış olduklarını beyan eder.

\section{KAYNAKLAR}

Althaus MM, Leal L, Silveira F, Zuffellato-Ribas KC, Ribas LLF, 2005. Cutting of the Berberis laurina Billb. using different concentrations of indolebutyric acid. Pesquisa Florestal Brasileira, Colombo, 50: 99-105.

Arslan N, Gürbüz B, Yilmaz G, 1994. Effects of Different Media on Rooting of Sage. Gaziosmanpaşa Üniversitesi, Ziraat Fakültesi Dergisi, 11 (1994): 125-130.

Atıcı, A, 2000. Biberiye (Rosmarinus officinalis L.) Çeliklerinin Köklenmesine NAA'in Etkisi, Ankara Üniversitesi, Fen Bilimleri Enstitüsü Yüksek Lisans Tezi (Basılmış).

Ayanoğlu F, Mert A, Kaya DA, 1999. Farklı IBA Dozlarının Doğal Olarak Yetişen Bazı Uçucu Yağ Bitkilerinin Köklenmeleri Üzerine Etkileri. Proceedings of 1st International Symposium on Protection of Natural Environment \& Ehrami Karaçam, Kütahya, 373-378.

Baydar H, 2009. Tibbi ve Aromatik Bitkiler Bilimi ve Teknolojisi (Genişletilmiş 3. Baskı). Süleyman Demirel Üniversitesi Yayınları No: 51, s:194-212, Isparta-Türkiye.

Baydar H, 2019. Tibbi ve Aromatik Bitkiler Bilim ve Teknolojisi 6. Baskı. Syf:409.

Bhat AB, Siddique MAA, Bhat ZA, 2008. Effect of IBA, NAA and Rootex On Rooting of Lavandula officinalis. Environment and Ecology 26 (4A): 1777-1781.

Chauhan VK, Jagmohan S, Srivastava IJ, Singh J, 1992. Initation of Rooting in Stem Cutting of Rosemary Through Hormonal Treatments. Indian Journal of Forestry, 15 (2): 131-135.

Çağıl HM, Uzunoğlu F, Mavi K, 2019. Farklı ortamların Berberis thunbergii cv. 'Atropurpurea' türünde çelik köklenmesi üzerine etkileri. Mustafa Kemal Üniversitesi Tarım Bilimleri Dergisi, 24 (3):181-187.

Eed AM, Burgoyne AH, 2015. Propagation of Simmondsia chinensis (Link) Schneider by stem cuttings. Biological and Chemical Research, (2015): 268-275.

Eriş A, 2003. Bahçe Bitkileri Fizyolojisi. Uludağ Üniversitesi Ziraat Fak. Ders Notları, No. 11, 152s. BursaTürkiye.

Herro E, Jacob SE, 2010. Mentha piperita (Peppermint). Product Allergen Watch, 21 (6): 327-329.

Ilgın M, Bulat L, 2001. GF-677 Klon Anacında Çelik Alma Zamanı İle Farklı Dozlardaki IBA (Indol-3 bütirik asit) Uygulamalarının Köklenme Başarısına Etkileri. Alatarım, 13 (2):15-22.

İzgi MN, 2020. Farklı IBA (İndol-3-Bütirik Asit) Dozları ve Köklendirme Ortamlarının Bazı Tıbbi Bitkilerin Köklenmesi Üzerine Etkileri. Türkiye Tarımsal Araştırmalar Dergisi, 7 (1): 9-16.

Kaçar O, Azkan N, Çöplü N, 2009. Effects of different rooting media and indole butyric acid on rooting of stem cuttings in sage (Salvia officinalis L. and Salvia triloba L.). Journal of Food, Agriculture and Environment, 7 (3/4): 349-352.

Kalyoncu İH, 1996. Konya Yöresindeki Kızılcık (Cornus mas L.) Tiplerinin Bazı Özellikleri ve Farklı Nem Ortamlarındaki Köklenme Durumu Üzerine Bir Araştırma, Selçuk Üniversitesi Tarımsal Yapılar ve Sulama Anabilim Dalı, Doktora Tezi, (Basılmış).

Kalyoncu IH, Ersoy N, Yilmaz M, Aydın M, 2009. Effects of humidity level and IBA dose application on the softwood top cuttings of white mulberry (Morus alba L.) and black mulberry (Morus nigra L.) types. African Journal of Biotechnology, 8 (16): 3754 -3760.

Kalyoncu İH, Ersoy N, Alparslan F, 2016. Ada Çayı (Salvia officinalis L.)'nın Yeşil Çelikle Çoğaltılması Üzerine Farklı Nem Ve Hormon Doz Uygulamalarının Etkileri. Selçuk Tarım Bilimleri Dergisi, 3 (2): 171-176.

Kanimarani SMA, 2013. Effect of soil media on the rooting of Myrtus communes and Berberis thunbergii semihardwood cuttings. IOSR Journal of Agriculture and Veterinary Science, 5 (4): 2319-2372. 
Kara N, Baydar H, Erbaş S, 2011. Farklı Çelik Alma Dönemleri ve IBA Dozlarının Bazı Tıbbi Bitkilerin Köklenmesi Üzerine Etkileri. Batı Akdeniz Tarımsal Araştırma Enstitüsü Derim Dergisi, 28 (2):71-81.

Kelen M, Demirtaş İ, 2001. 5 BB ve 420 A Amerikan Asma Anaçlarının Köklenme Oranları ve Kök Kaliteleri Üzerine Farklı Köklendirme Ortamları ile IBA Dozlarının Etkileri. Tarım Bilimleri Dergisi, 7 (1): 142-146.

Kumlay AM, Eryiğit T, 2011. Bitkilerde Büyüme ve Gelişmeyi Düzenleyici Maddeler: Bitki Hormonları. Iğdır Üniversitesi Fen Bilimleri Enstitüsü Dergisi, 1 (2): 47-56.

Kuris A, Altman A, Putievsky E, 1980. Rooting and initial establishment of stem cuttings of oregano, peppermint and balm. Scientia Horticulturae, 13 (1980): 53-59.

McKay DL, Blumberg JB, 2006. A Review of the Bioactivity and Potential Health Benefits of Peppermint Tea (Mentha piperita L.). Phytother Research, 20: 619-633.

Özcan, İ̇, Arabacı O, Öğretmen NG, 2013. Lavanta (Lavandula hybrida)'nın köklenmesi üzerine farklı hormon dozları ve köklendirme ortamlarının etkisi. V. Süs Bitkileri Kongresi, Bildiriler Kitabı, 06-09 Mayıs, Yalova, s. 529.

Pulatkan M, Yıldırım N, Kaya Şahin E, 2018. Farklı hormon uygulamalarının Berberis thunbergii “Atropurpurea Nana" çeliklerinin köklenmesi üzerine etkisi. Türkiye Ormancılık Dergisi, 19 (4): 386-390.

Sağlam AC, Yaver S, Başer İ, Cinkılıç L, 2014. The Effects of Different Hormones and Their Doses on Rooting of Stem Cuttings in Anatolian Sage (Salvia fruticosa Mill.). APCBEE Procedia, 8 (2014): 348-353.

Sarı Y, Kaçar O, 2019. Biberiye (Rosmarinus officinalis L.) Çeliklerinde Köklenme Üzerine Farklı Köklendirme Ortamları ve IBA Dozlarının Etkileri. Bahçe, 48 (1):27-37.

Singh R, Shushni MAM, Belkheir A, 2015. Antibacterial and antioxidant activities of Mentha piperita L. Arabian Journal of Chemistry, 8 (3):322-328.

Şekeroğlu N, Kırpık M, Özgüven M, 2001. Effects of different rooting media and IBA concentrations on rooting of Thymbra spicata L. Workshop on Agricultural and Quality Aspects of Medicinal and Aromatic Plants. May 29-June 1, 2001, Adana.

Uysal F, Atmaca S, Kolak B, 2010. Biberiye (Rosmarinus officinalis L.) çeliklerinin köklenme kalitesi üzerine farklı NAA dozları ve köklendirme ortamlarının etkileri. IV. Süs Bitkileri Kongresi Bildiri Kitabı, 20-22 Ekim 2010. Mersin.

Üre T, 2000. Bazı mercanköşk (Origanum sp) türlerinin gövde çeliklerinin köklenmesi üzerine indol butirik asidin (IBA) etkisi. Ankara Üniversitesi Fen Bilimleri Enstitüsü Tarla Bitkileri Anabilim Dalı, Yüksek Lisans Tezi (Basılmış).

Yavaşi A, 2012. Çay Çeliklerinin Köklendirilmesinde Ortam, Ph ve Hormonların Etkileri. Ondokuz Mayıs Üniversitesi Fen Bilimleri Enstitüsü, Yüksek Lisans Tezi (Basılmış). 